\title{
Oral health knowledge and practices of clinical medical and dental students in a North- Eastern Nigerian University.
}

\author{
${ }^{1}$ Janada Y., ${ }^{2}$ Ikhodaro I. P, ${ }^{3}$ Ibiyemi O.
}

${ }^{1}$ Department of Preventive Dentistry, Faculty of Dentistry, University of Maiduguri, Nigeria.

${ }^{2}$ Department of Restorative Dentistry, Faculty of Dentistry, University of Maiduguri, Nigeria.

${ }^{3}$ Department of Periodontology and Community Dentistry, Faculty of Dentistry, University of Ibadan, Nigeria.

\begin{abstract}
Objective: Medical and dental students as future health care professionals should be aware of adequate oral health care. Therefore, this study aimed to determine the knowledge and practices of oral health of clinical medical and dental students in a North-Eastern Nigerian University.

Methods: Cross sectional study involving 150 students, comprising 107 medical and 43 dental students. They were interviewed on knowledge of oral health care, oral health practices and psychosocial impact of oral health using an interviewer-administered questionnaire. The students were further examined for dental caries and their oral hygiene status. The Student $t$-test was used to compare means while Chisquare test was used to test associations between categorical variables at $\mathrm{p}<0.05$.
\end{abstract}

Results: The mean \pm SD age of the students was 24.5 , males constituted $61.3 \%$. One hundred and twentysix (84.0\%) students had good knowledge of oral health care. Forty-two (97.7\%) of the dental students had good knowledge while $84(78.5 \%)$ of the medical students had good knowledge ( $p=0.003)$. Twenty $(46.5 \%)$ and $60(56.1 \%)$ of dental and medical students respectively had poor oral health practice $(\mathrm{p}=0.32$ ). Mean \pm SD psychosocial impact score was $1.26 \pm 2.06$ and $1.53 \pm 2.34$ for dental and medical students respectively $(\mathrm{p}=0.68)$.

The prevalence of dental caries and poor oral hygiene was $15(34.9 \%)$ and $23(53.5 \%)$ for dental students. The corresponding value for medical students were $30(28.0 \%)$ and 51(47.6\%).

Conclusions: There was good knowledge of oral health care among these students. Dental students had better knowledge of oral health care than medical students. They also had better oral health care practices and lower psychosocial impact of oral health than medical students though not statistically significant. Overall, younger age group of students reported higher psychosocial impact of oral health care on daily activities than older ones.

Key words: Oral health, knowledge, behaviour, medical, dental, students, Nigeria.

INTRODUCTION: Oral health is an integral part of general health which can be maintained by oral selfcare. . It is the professional responsibility of doctors and dentists to inform patients about appropriate health habits as well as raising their awareness about how to prevent diseases. To adequately raise patients' awareness about how to prevent diseases, doctors and dentist must adopt appropriate and adequate health attitudes and behaviours during their undergraduate medical and dental education since they are future

Correspondence: Ibiyemi O.

Department of Periodontology and Community

Dentistry, University of Ibadan, Nigeria

Email: shola_ibiyemi@yahoo.com

Tel: +2348037201253

Received: 17/12/2018

Accepted: 25/04/2019

https://dx.doi.org/10.4314/ajoh.v9i1.5 health professionals. Oral health knowledge and practice of medical and dental students may affect their oral self-care habits ${ }^{1}$. For the dental students, as the future providers of dental care, it may also potentially influence their patients' ability to take care of their teeth ${ }^{2}$ and shape the public's oral health education level ${ }^{3}$. Undergraduate medical and dental education should include comprehensive preventive oral health care curriculum that will ensure that students institute oral self-care regimens and also empower them to motivate patients for oral self-care. Such educational initiative should enable medical and dental students develop stable health behaviors ${ }^{4}$ which are not influenced by individual characteristics. ${ }^{5,6}$ The relationship between knowledge, attitude and practice has been previously observed and this relationship seems to be stronger among dental students ${ }^{7,8}$ and dentists ${ }^{6}$ compared to lay people. Some studies demonstrated the place and 
importance of socio-demographic factors and socialization processes on tooth brushing. For example, the frequency of tooth brushing among female dental students were higher than in male dental students in Greece ${ }^{5}$ and Jordan ${ }^{9}$ while in some studies there was no gender differences in tooth brushing among Japanese and Finnish dental students ${ }^{10}$ and USA and Korean Students ${ }^{11.12}$ Promotion of preventive oral health care practices can be determined by understanding how much value medical and dental students place on prevention which will be reflected in the adoption of preventive oral health care practices for themselves. Therefore, it is important that their own oral health knowledge is good and their oral health practices conform to professional recommendations. Only one study reported determinants of preventive oral health behavior among final year dental students in Nigeria ${ }^{1}$ and there is dearth of this information among medical students. With proper knowledge of oral health and good oral health practices they can play an important role in the health education of individuals and groups $^{13}$.

\section{MTHODS}

A cross-sectional study was undertaken among undergraduate medical and dental students of the University of Maiduguri, Nigeria from May to June 2017. The University of Maiduguri is the first university in North-Eastern Nigeria, established in 1975. The undergraduate medical and dental programmes are six years in duration consisting of three years each in both pre-clinical and clinical studies. These students completed a self-administered semi-structured questionnaire that assessed sociodemographic characteristics, knowledge of oral health care, oral health care practices and psychosocial impact of oral health. For the knowledge score, a score of 1 was allotted to the answer to each variable while for the dietary and oral health care practice score, a score ranging from 1-6 was allotted to the options of each variable based on (1-never, 2-several times monthly, 3-once weekly, 4-sometimes weekly, 5-every day and 6-several times daily). Total obtainable mark for knowledge of oral health care was 13 points with poor, fair and good knowledge scoring 0-5, 6-10 and 11-13 respectively. Total obtainable mark for oral health care practices was 81 points with good and poor practice scoring 43-58 and 59-81 respectively. For the psychosocial impact score, a score ranging from 0-3 was allotted to the options of each variable based on frequency of occurrence of the risk (0- no, 1sometimes, 2-fairly often and 3-very often). Total obtainable mark for psychosocial impact of oral health was 10 points with low and high psychosocial impact scoring 0-2 and 3-10 respectively. Prior to administration of the questionnaire that was developed, the intended objectives of the questionnaire items against the study objectives were validated by two senior academics. These academics also assessed the questionnaire's applicability, efficiency and clarity in terms of the use of appropriate language. Minor modifications were made to the questionnaire following the content validation. Next, the questionnaire was pre-tested among students of medical laboratory science who had similar sociodemographic characteristics with the study population to verify and ascertain its comprehensiveness and face validity before its final administration. Slight modifications to the questionnaire were made after the pretest. After completing the questionnaire, the participants were examined by using the WHO Adult Assessment Form $^{15}$. The examination was undertaken using mouth mirrors and wooden spatulas by the two examiners who were trained and calibrated to use the diagnostic criteria for dental caries and oral hygiene status ${ }^{15}$. To determine both intra-examiner and interexaminer agreement, $10 \%$ of the study participants were reexamined. The data was entered into a computer and analyzed using IBM Statistical Package for Social Science (SPSS) version 21 (SPSS Inc. Chicago 2012). Frequencies and means were generated. Cohen's Kappa was used to determined intraexaminer and intra-examiner variability. The Student t-test was used to compare means while the Chisquare test was used to test associations between categorical variables at $p<0.05$. For analytical purpose, age was categorized into $20-24$ years and $25-37$ years; and year of study into 4 th and 5 th year; and 6th year. The study was undertaken as part of the curriculum requirement for the award of the Bachelor of Dental Surgery, therefore to undertake the study was obtained from the Dean Faculty of Dentistry, University of Maiduguri, Nigeria. Ethical approval was obtained from the University of Maiduguri Ethical Review Committee. The study was undertaken in strict compliance with Helsinki Declaration principles on studies involving human subjects. 
Table 1: Demographic characteristics of study participants

\begin{tabular}{lccc}
\hline $\begin{array}{l}\text { Demographic } \\
\text { characteristics }\end{array}$ & $\begin{array}{c}\text { Overall } \\
\mathbf{N}(\%)\end{array}$ & $\begin{array}{c}\text { Dentistry } \\
\mathbf{N}(\%)\end{array}$ & $\begin{array}{c}\text { Medicine } \\
\mathbf{N}(\%)\end{array}$ \\
\hline $\begin{array}{l}\text { Age group (years) } \\
20-24\end{array}$ & $92(61.3)$ & $27(29.3)$ & $65(70.7)$ \\
$25-37$ & $58(28.7)$ & $16(27.6)$ & $42(72.4)$ \\
\hline Gender & & & \\
Male & $92(61.3)$ & $30(32.6)$ & $62(67.4)$ \\
Female & $58(28.7)$ & $13(22.4)$ & $45(77.6)$ \\
Year of study & & & \\
$4^{\text {th }}$ & $42(28.0)$ & $14(32.6)$ & $28(26.2)$ \\
$5^{\text {th }}$ & $69(46.0)$ & $21(48.8)$ & $48(44.9)$ \\
$6^{\text {th }}$ & $39(26.0)$ & $8(18.6)$ & $31(29.0)$ \\
\hline
\end{tabular}

Table 2: Assessment of knowledge on oral health among study participants

\begin{tabular}{|c|c|c|c|c|c|c|}
\hline \multirow[t]{2}{*}{ Knowledge on oral health } & \multicolumn{2}{|l|}{ Dentistry } & \multicolumn{2}{|l|}{ Medicine } & \multicolumn{2}{|c|}{ Overall } \\
\hline & $\mathrm{N}(\%)$ & $\mathrm{N}(\%)$ & $\mathrm{N}(\%)$ & $\mathbf{N}(\%)$ & $\mathrm{N}(\%)$ & $\mathrm{N}(\%)$ \\
\hline Toothbrush can be changed after 3 months & $40(93.0)^{\mathrm{a}}$ & $3(7.0)$ & $97(90.7)^{\mathrm{a}}$ & $10(9.3)$ & $137(91.3)^{\mathrm{a}}$ & a $13(8.7)$ \\
\hline Soft/medium bristled toothbrush better than hard bristled toothbrush & $42(97.7)^{\mathrm{a}}$ & $1(2.3)$ & $88(82.2)^{\mathrm{a}}$ & 19(17.8) & $130(86.7)^{\mathrm{a}}$ & a $20(13.3)$ \\
\hline Fluoride toothpaste prevents dental caries & $42(97.7)^{\mathrm{a}}$ & $1(2.3)$ & $98(91.6)^{a}$ & $9(8.4)$ & $140(93.3)^{\mathrm{a}}$ & a $10(6.7)$ \\
\hline Plaque is one of the aetiological factors of dental caries & $43(100.0)^{\mathrm{a}}$ & $0(0.0)$ & $101(94.4)^{\mathrm{a}}$ & $6(5.6)$ & $139(92.7)^{\mathrm{a}}$ & a $11(7.3)$ \\
\hline Carbonated drinks affect teeth adversely & $43(100.0)^{\mathrm{a}}$ & $(0.0)$ & $82(76.6)^{\mathrm{a}}$ & $25(24.4)$ & $125(83.3)^{\mathrm{a}}$ & a $25(16.7)$ \\
\hline Some oral problems can lead to systemic diseases & $42(97.7)^{\mathrm{a}}$ & $1(2.3)$ & $99(92.5)^{\mathrm{a}}$ & $8(7.5)$ & $141(94.0)^{\mathrm{a}}$ & a $9(6.0)$ \\
\hline Gum bleeds when it is inflamed & $37(86.0)^{\mathrm{a}}$ & $6(14.0)$ & $78(72.9)^{\mathrm{a}}$ & $29(17.1)$ & $115(76.7)^{\mathrm{a}}$ & a $35(23.3)$ \\
\hline Decayed anterior teeth cannot affect tooth appearance & $43(100.0)$ & $0(0.0)^{\mathrm{a}}$ & 105(98.1) & $2(1.9)^{\mathrm{a}}$ & $148(98.7)$ & $2(1.3)^{\mathrm{a}}$ \\
\hline Smoking causes oral health problems & $41(95.3)^{\mathrm{a}}$ & $2(4.7)$ & $103(96.3)^{\mathrm{a}}$ & $4(3.7)$ & $144(96.0)^{\mathrm{a}}$ & a $6(4.0)$ \\
\hline High intake of sugary diets is one of the aetiological factors of dental caries & $42(97.7)^{\mathrm{a}}$ & $1(2.3)$ & $97(90.7)^{\mathrm{a}}$ & $10(9.3)$ & $139(92.7)^{\mathrm{a}}$ & a $11(7.3)$ \\
\hline Regular visit to the dentist is not important & $42(97.7)$ & $1(2.3)^{\mathrm{a}}$ & $87(81.3)$ & $20(18.7)^{\mathrm{a}}$ & $129(86.0)$ & $21(14.0)^{a}$ \\
\hline
\end{tabular}

${ }^{a}$ Correct answers to respective statements

Table 3: Knowledge of the study participants on oral health by demographic characteristics

\begin{tabular}{|c|c|c|c|c|c|c|c|c|c|}
\hline $\begin{array}{l}\text { Demographic } \\
\text { characteristics }\end{array}$ & $\begin{array}{l}\text { Overall } \\
n(\%)\end{array}$ & $\begin{array}{l}\text { Mean } \pm \text { SD } \\
\text { Knowledge scor }\end{array}$ & $\mathrm{t}$ & $\mathrm{p}^{*}$ & $\begin{array}{l}\text { Fair } \\
\text { knowledge } \\
\mathrm{N}(\%)\end{array}$ & $\begin{array}{l}\text { Good } \\
\text { knowledge } \\
\mathrm{N}(\%)\end{array}$ & $x^{2}$ & $\mathrm{p}^{\#}$ & OR( $(95 \% \mathrm{CI})$ \\
\hline $\begin{array}{l}\text { Age group (years) } \\
20-24 \\
25-37\end{array}$ & $\begin{array}{l}92(61.3) \\
58(28.7)\end{array}$ & $\begin{array}{l}11.73 \pm 1.43 \\
12.07 \pm 1.09\end{array}$ & -1.55 & 0.12 & $\begin{array}{l}18(19.6) \\
6(10.3)\end{array}$ & $\begin{array}{l}74(80.4) \\
52(89.7)\end{array}$ & 2.25 & 0.17 & $2.11(0.78-5.67)$ \\
\hline $\begin{array}{l}\text { Gender } \\
\text { Male } \\
\text { Female }\end{array}$ & $\begin{array}{l}92(61.3) \\
58(28.7)\end{array}$ & $\begin{array}{l}11.88 \pm 1.38 \\
11.83 \pm 1.22\end{array}$ & 0.24 & 0.81 & $\begin{array}{r}15(16.3) \\
9(15.5)\end{array}$ & $\begin{array}{l}77(83.7) \\
49(84.5)\end{array}$ & 0.02 & 1.00 & $1.06(0.43-2.61)$ \\
\hline $\begin{array}{l}\text { Course of study } \\
\text { Dentistry } \\
\text { Medicine }\end{array}$ & $\begin{array}{r}43(28.7) \\
107(71.3)\end{array}$ & $\begin{array}{l}12.60 \pm 0.79 \\
11.56 \pm 1.37\end{array}$ & 4.69 & $\begin{array}{c}< \\
0.0001\end{array}$ & $\begin{array}{r}1(2.3) \\
23(21.5)\end{array}$ & $\begin{array}{l}42(97.7) \\
84(78.5)\end{array}$ & 8.39 & 0.003 & $0.09(0.01-0.67)$ \\
\hline $\begin{array}{l}\text { Year of study } \\
4^{\text {th } \& 5^{\text {th }} \text { year }} \\
6^{\text {th }} \text { year }\end{array}$ & $\begin{array}{r}111(74.0) \\
39(26.0)\end{array}$ & $\begin{array}{l}11.85 \pm 1.36 \\
11.90 \pm 1.19\end{array}$ & 0.21 & 0.84 & $\begin{array}{r}18(16.2) \\
6(15.4)\end{array}$ & $\begin{array}{l}93(83.8) \\
33(84.6)\end{array}$ & 0.02 & 1.00 & $1.07(0.39-2.51)$ \\
\hline
\end{tabular}


Table 4: Tooth cleaning devices used by study participants

\begin{tabular}{lcrc}
\hline Tooth cleanin g devices & Overall & Dentistry & Medicine \\
& $\mathbf{n}(\%)$ & $\mathbf{N}(\%)$ & $\mathbf{N}(\%)$ \\
\hline Toothbrush including toothpaste only & $107(71.3 \%)$ & $33(76.7)$ & $74(69.2)$ \\
\hline Toothbrush including toothpaste + Wooden toothpick & $16(10.7)$ & $3(7.0)$ & $11(10.3)$ \\
Toothbrush including toothpaste + Chewing stick & $14(9.3)$ & $3(7.0)$ & $13(12.1)$ \\
Toothbrush including toothpaste + dental floss & $13(8.7)$ & $4(9.3)$ & $9(8.4)$ \\
\hline
\end{tabular}

Table 5: Dietary and tobacco products use practices among study participants

\begin{tabular}{|c|c|c|c|c|c|c|}
\hline \multirow[t]{3}{*}{ Dietary and tobacco products use practices } & \multicolumn{2}{|c|}{ Dentistry } & \multicolumn{2}{|c|}{ Medicine } & \multicolumn{2}{|c|}{ Overall } \\
\hline & Yes & Seldom/No & Yes & Seldom/No & Yes & Seldom/No \\
\hline & $\mathrm{N}(\%)$ & $\mathrm{N}(\%)$ & $\mathrm{N}(\%)$ & $\mathrm{N}(\%)$ & $\mathrm{N}(\%)$ & $\mathrm{N}(\%)$ \\
\hline Fresh fruits intake & 39(90.7) & $4(9.3)$ & 105(98.1) & $2(1.9)$ & $144(96.0)$ & $6(4.0)$ \\
\hline Biscuits and cakes intake & $33(76.7)$ & $10(23.3)$ & $100(93.5)$ & $7(6.5)$ & 133(88.7) & $17(11.3)$ \\
\hline Intake of Pies, Buns, eggroll and fish roll & $35(81.4)$ & $8(18.6)$ & $89(83.2)$ & $18(16.8)$ & $124(82.7)$ & $26(17.3)$ \\
\hline Intake of Jam or honey & 15(34.9) & $28(65.1)$ & $51(47.7)$ & $56(52.3)$ & $66(44.0)$ & $84(56.0)$ \\
\hline Chewing gums containing sugar & $32(74.4)$ & $11(25.6)$ & $90(84.1)$ & $17(15.9)$ & $122(81.3)$ & $28(18.7)$ \\
\hline Intake of sweets & $34(79.1)$ & $9(20.9)$ & 101(94.4) & $6(5.6)$ & $135(90.0)$ & $15(10.0)$ \\
\hline Intake carbonated drinks & $38(80.4)$ & $5(11.6)$ & $100(93.5)$ & $7(6.5)$ & $138(92.0)$ & $12(8.0)$ \\
\hline Tea with sugar intake & $39(90.7)$ & $4(9.3)$ & 101(94.4) & $6(5.6)$ & $140(93.3)$ & $10(6.7)$ \\
\hline Smoke cigarette & $1(2.3)$ & $42(97.7)$ & $1(0.7)$ & 106(99.1) & $2(1.3)$ & 148(98.7) \\
\hline Pipe tobacco & $0(0.0)$ & $43(100.0)$ & $1(0.7)$ & 106(99.1) & $1(0.7)$ & 149(99.3) \\
\hline Chew tobacco & $0(0.0)$ & $43(100.0)$ & $1(0.7)$ & 106(99.1) & $1(0.7)$ & 149(99.3) \\
\hline Use snuff & $0(0.0)$ & $43(100.0)$ & $0(0.0)$ & 107(100.0) & $0(0.0)$ & $150(100.0)$ \\
\hline
\end{tabular}


Table 6: Oral health practices of the study participants compared by demographic characteristics

\begin{tabular}{|c|c|c|c|c|c|c|c|c|c|}
\hline $\begin{array}{l}\text { Demographic } \\
\text { characteristics }\end{array}$ & $\begin{array}{c}\text { Overall } \\
\text { n(\%) }\end{array}$ & \multicolumn{2}{|c|}{$\begin{array}{l}\text { Mean } \pm \text { SD oral health } \\
\text { practice score }\end{array}$} & \multirow[t]{2}{*}{$\mathrm{p}^{*}$} & \multirow[t]{2}{*}{$\begin{array}{l}\text { Poor } \\
\text { practice } \\
\text { N(\%) }\end{array}$} & \multirow[t]{2}{*}{$\begin{array}{l}\text { Good practice } \\
\mathbf{N}(\%)\end{array}$} & $x^{2}$ & p\# & OR $(95 \%$ CI $)$ \\
\hline \multicolumn{7}{|c|}{ Age group (years) } & & & \\
\hline $20-24$ & $92(61.3)$ & $59.21 \pm 7.67$ & -0.78 & 0.44 & $47(51.1)$ & $45(48.9)$ & 0.48 & 0.51 & $1.26(0.6-52.45)$ \\
\hline $25-37$ & $58(28.7)$ & $60.21 \pm 7.66$ & & & $33(56.9)$ & $25(43.1)$ & & & \\
\hline \multicolumn{10}{|l|}{ Gender } \\
\hline Male & $92(61.3)$ & $60.44 \pm 7.69$ & 1.80 & 0.08 & $54(58.7)$ & $38(41.3)$ & 2.75 & 0.13 & $0.57(0.3-01.11)$ \\
\hline Female & $58(28.7)$ & $58.19 \pm 7.47$ & & & $26(44.8)$ & $32(55.2)$ & & & \\
\hline \multicolumn{10}{|l|}{ Course of study } \\
\hline Dentistry & $43(28.7)$ & $59.33 \pm 7.98$ & -0.27 & 0.79 & $20(46.5)$ & $23(53.5)$ & 1.13 & 0.37 & $1.45(0.7-22.99)$ \\
\hline Medicine & $107(71.3)$ & $59.70 \pm 7.56$ & & & $60(56.1)$ & $47(43.9)$ & & & \\
\hline \multicolumn{10}{|l|}{ Year of study } \\
\hline $4^{\text {th }} \& 5^{\text {th }}$ year & $111(74.0)$ & $59.56 \pm 8.18$ & -0.09 & 0.93 & $57(51.4)$ & $54(48.6)$ & 0.67 & 0.46 & $.36(0.6-52.85)$ \\
\hline $6^{\text {th }}$ year & $39(26.0)$ & $59.69 \pm 6.01$ & & & $23(59.0)$ & $16(41.0)$ & & & \\
\hline
\end{tabular}

Note: $\because$ independent Student $\mathrm{t}$ test; \# - Chisquare test

Table 7: Psychosocial impact of oral health on daily activities of the study participants by demographic characteristics

\begin{tabular}{|c|c|c|c|c|c|c|c|c|c|}
\hline $\begin{array}{l}\text { Demographic } \\
\text { characteristics }\end{array}$ & $\begin{array}{l}\text { Overall } \\
\text { n(\%) }\end{array}$ & $\begin{array}{l}\text { Mean } ₫ \text { SD psychosocial } \\
\text { impact score }\end{array}$ & $\mathbf{t}$ & $\mathrm{p}^{*}$ & $\begin{array}{c}\text { Low } \\
\text { Psychosocial } \\
\text { impact N(\%) }\end{array}$ & $\begin{array}{c}\text { High } \\
\text { psychosocial } \\
\text { impact N(\%) }\end{array}$ & $x^{2}$ & p\# & OR $(95 \% \mathrm{CI})$ \\
\hline $\begin{array}{l}\text { Age group (years) } \\
20-24 \\
25-37\end{array}$ & $\begin{array}{l}92(61.3) \\
58(28.7)\end{array}$ & $\begin{array}{l}1.85 \pm 2.50 \\
0.83 \pm 1.64\end{array}$ & 2.75 & 0.007 & $\begin{array}{l}68(73.9) \\
53(91.4)\end{array}$ & $\begin{array}{l}24(26.1) \\
5(8.6)\end{array}$ & 6.96 & 0.01 & $0.27(0.10-0.75)$ \\
\hline $\begin{array}{l}\text { Gender } \\
\text { Male } \\
\text { Female }\end{array}$ & $\begin{array}{l}92(61.3) \\
58(28.7)\end{array}$ & $\begin{array}{l}1.24 \pm 1.96 \\
1.79 \pm 2.65\end{array}$ & -1.47 & 0.14 & $\begin{array}{l}77(83.7) \\
44(75.9)\end{array}$ & $\begin{array}{l}15(16.3) \\
14(24.1)\end{array}$ & 1.40 & 0.29 & $1.63(0.72-3.70)$ \\
\hline $\begin{array}{l}\text { Course of study } \\
\text { Dentistry } \\
\text { Medicine }\end{array}$ & $\begin{array}{c}43(28.7) \\
107(71.3)\end{array}$ & $\begin{array}{l}1.26 \pm 2.06 \\
1.53 \pm 2.34\end{array}$ & 0.68 & 0.59 & $\begin{array}{l}36(83.7) \\
85(79.4)\end{array}$ & $\begin{array}{r}7(16.3) \\
22(20.6)\end{array}$ & 0.36 & 0.65 & $1.33(0.52-3.39)$ \\
\hline $\begin{array}{l}\text { Year of study } \\
4^{\text {th }} \& 5^{\text {th }} \text { year } \\
6^{\text {th }} \text { year }\end{array}$ & $\begin{array}{l}111(74.0) \\
39(26.0)\end{array}$ & $\begin{array}{l}1.62 \pm 2.48 \\
0.97 \pm 1.37\end{array}$ & 1.55 & 0.12 & $\begin{array}{l}86(77.5) \\
35(89.7)\end{array}$ & $\begin{array}{c}25(22.5) \\
4(10.3)\end{array}$ & 2.78 & 0.11 & $0.39(0.13-1.21)$ \\
\hline
\end{tabular}

Note: * - independent Student t-test; \# - Chi-square test 


\section{RESULTS}

The mean \pm SD age of the students was $24.5 \pm 2.70$ years. The students comprise 107 (71.3\%) medical students and $43(28.7 \%)$ dental students. Table 1 shows that the majority $92(61.3 \%)$ of the students were aged 20 to 24 , males constituted $92(61.3 \%)$ and the majority $69(46.0 \%)$ were in the 5 th year. Table 2 shows assessment of knowledge on oral health among study participants. Over $86.0 \%$ and $72 \%$ of dental and medical students respectively reported correct knowledge of oral health. The mean \pm SD knowledge score of oral health of the students was $11.86 \pm 1.32$, twenty-four $(16.0 \%)$ and $126(84.0 \%)$ of the students had fair and good knowledge of oral health respectively. When the knowledge of the students on oral health was compared by demographic characteristics using independent Student t-test, only the course of study had a statistically significant association with mean SD knowledge score (Table 3). The dental students had a higher (12.60 0.79) mean SD knowledge score than medical students (11.56 1.37). Similarly, when Chi-square test was used to compare categories of knowledge and sociodemographic characteristics, $97.7 \%$ and $78.5 \%$ of dental students and medical students had good knowledge respectively $(p=0.003)$. There was a statistical significant difference in course of study and whether soft/medium textured tooth brush is better than hard textured. Forty-two (97.7\%) and 88 (82.2\%) of dental and medical students respectively reported that soft/medium textured toothbrush is better than hard textured toothbrush. Eighty-two (54.7\%) of the students had visited a dentist before, out of which 24 $(29.3 \%), 21(25.6 \%)$ and $19(23.2 \%)$ participants last visited a dentist because of treatment, follow up, and toothache respectively. Eighty-two (54.7\%) of students cleaned their teeth twice daily and $12(8 \%)$ cleaned their teeth for less than 1 minute. Table 4 shows that overall, the majority $107(71.3 \%)$ of students cleaned their teeth with toothbrush including toothpaste only with $33(76.7 \%)$ and $74(69.2 \%)$ as the corresponding figures for dental and medical students. Table 5 shows that overall; one form of cariogenic diet was consumed by between $44.0 \%$ and $96.0 \%$ of students with dental students accounting for between $34.9 \%$ and $90.7 \%$ while medical students accounted for between $47.7 \%$ and $98.1 \%$. More than $98.0 \%$ of the students do not smoke cigarette or pipe, chew tobacco or use snuff. The mean \pm SD practice score for the students was $59.6 \pm 7.7$. Table 6 shows that the mean \pm SD practice score of dental students was $59.33 \pm 7.98$ while for medical students it was 59.70 $\pm 7.56(p=0.79)$. Seventy $(46.7 \%)$ and $80(53.3 \%)$ students had good and poor scores for oral health practice respectively. Table 6 also shows no statistical significant association between oral health practices and demographic characteristics of the students ( $p>0.05$ ). Twenty $(46.5 \%$ ) and $60(56.1 \%$ ) of dental and medical students respectively had poor oral health practice $(p=0.32)$. The mean $\pm S D$ and median (minimum, maximum) psychosocial impact score of students was $1.5 \pm 2.3$ and $0.5(0,10)$ respectively. Table 7 shows that only age group was statistically significantly associated with psychosocial impact $(p<0.05)$. The mean \pm SD psychosocial impact score of younger age group, 20-24 years, was $1.85 \pm 2.50$ while it was $0.83 \pm 1.64$ for older age group $(\mathrm{p}=0.007)$. Table 7 shows that $26.1 \%$ of participants in the younger age group and $8.6 \%$ of older age group, 25-37 years, reported high psychosocial impact of oral health on daily activities $(p=0.01)$. Mean $\pm S D$ psychosocial impact score was $1.26 \pm 2.06$ and $1.53 \pm 2.34$ for dental students and medical students respectively $(p=0.68)$. Thirty (20.0\%) and $26(17.3 \%)$ students described the health of their teeth and gum respectively as average or poor. Three $(2.0 \%)$ students reported that they want their oral health improved. The measure of agreement was $0.94(94 \%)$ for intra-examiner agreement and 0.91 (91\%) for inter-examiner agreements for dental caries, oral hygiene status, use of dentures, tooth fracture and presence of soft tissue lesions $(p<0.05)$. Forty-five $(30.0 \%)$ students had dental caries, with a mean \pm SD and median (minimum, maximum) DMFT of $0.5 \pm 1.2$ ) and $0(0,9)$ teeth respectively. The prevalence of dental caries was $15(34.9 \%)$ and $30(28.0 \%)$ for dental and medical students respectively. Seventy-four (49.3\%) students had poor oral hygiene, with dental students accounting for $23(53.5 \%)$ while medical students accounted for $51(47.6 \%)$.

\section{DISCUSSION}

In any Nigerian university, preventive medicine and dentistry courses that include good health practices are taught to clinical students. It is important to assess the impact of these courses on students' knowledge and behaviours of any health matter. Although the majority of previous studies on oral health knowledge and behaviours from different countries were undertaken among dental students ${ }^{1,2}$, very few 
studies ${ }^{16,17}$ had medical students included. However, to the best of our knowledge, this is the first Nigerian study exploring the oral health knowledge and behavior of both clinical year medical and dental students. In this study, a large proportion $(84.0 \%)$ of study participants had good knowledge of oral health and good knowledge score was reported more among dental students than medical students. In addition, the mean knowledge score on oral health care was higher among dental students than medical students in agreement with studies on oral health knowledge and behavior among clinical medical, dental and paramedical students in Manglore ${ }^{16}$ and Eastern India $^{17}$. Likewise, in a Saudi Arabian study on oral health knowledge, attitude and practice among dental and pharmacy students, higher knowledge scores were obtained from the former compared to the latter and this was believed to be due to information available to the dental students in their syllabus ${ }^{18}$. About half of the study participants in this present study had poor oral health practices and more medical students had poor oral practice than dental students though the difference was not statistically significant. About $9 \%$ of students did not know that toothbrush should be changed after three months. A previous study that evaluated oral-hygiene awareness and practice among dental students showed that $21.7 \%$ of dental students did not change their tooth brush after three months which might be a reflection of their knowledge of tooth brush use since knowledge sometimes influence practice ${ }^{19}$. Almost all dental and medical students were aware that soft bristled tooth brush is preferable to hard bristled tooth brush in a previous study that assessed knowledge, attitude, and practices among dental and medical students in Eastern India ${ }^{17}$. On the contrary, in this present study, $13.3 \%$ of the students did not know that soft or medium bristled toothbrush is better than hard bristled toothbrush. Those who were ignorant of this might use hard bristled toothbrush which might result in tooth wear and its consequences. An even higher proportion of medical and dental students (85\%) have been reported to more likely use hard-bristled toothbrush ${ }^{2}$. Fluoridated toothpaste use in the prevention of dental caries has been adequately studied and its use has been associated with the decline of dental caries in developed countries. However, in this study, about $7 \%$ of both group of students did not know that fluoridated toothpaste prevents dental caries which seems to agree with findings of $7.4 \%$ and $8 \%$ reported among medical and dental students in other previous studies ${ }^{16,18}$. Higher proportion $(53.7 \%)$ of dental students in a previous Nigerian study on determinants of preventive and oral health behaviour reported that they did not know that using fluoridated toothpaste is more important than the brushing per see for preventing caries ${ }^{1}$. Some students in this present study did not know what plaque is and the effect of plaque which might be another reason for not knowing that fluoridated toothpaste can remove plaque. Greater number of dental than medical students reported that soft or medium textured toothbrush is better than hard textured and that regular visit to the dentist is important, demonstrating the impact of training in preventive dentistry. Knowledge about the association between some oral problems and systemic diseases in the present study is similar to that reported in two other studies in Nigeria ${ }^{1}$ and India ${ }^{17}$ where $5 \%$ and $8 \%$ of the students respectively were unaware of this association. These findings are believed to be due to the heterogeneity of the study participants. Unlike the previous studies ${ }^{1,6}$, the present study included medical students whose curriculum does not include preventive oral health courses. Gender difference in oral health knowledge score favored males in contrast to other popular reports among students in Jordan and Manglore, India ${ }^{16}$ where females had better knowledge but consistent with findings among Iranian $^{3}$ and Indian ${ }^{20}$ students. The reason for this gender difference from our study is unknown but could be related to the high proportion of male students in relation to the female students and a result of cultural influence in our environment. In general, however, individual item responses among the students showed high oral health knowledge scores, with a good overall knowledge proportion of $84 \%$. The exception was in their responses to regular visits to the dentist, and effect of decayed teeth on tooth appearance. Only $1.3 \%$ of the students accepted that tooth decay could affect tooth appearance. The reason for this response could be due to the very low prevalence of caries among the anterior teeth, which are in the aesthetic zone of the mouth. Although many of the students had visited the dentist, and more than half of these had been prompted by dental problems, a large proportion of them erroneously agreed that "regular visits to the dentist is not important". In sharp contrast, many dental students in another study agreed or strongly agreed that regular dental 
checkups are important ${ }^{18}$. The reason for the observed differences might be due how important oral health care is to different people. As regular dental visits are taken to be visits made to the dentist for check-ups and prophylaxis, then our finding is supported by reports of up to $75 \%$ and $69 \%$ of dental and medical students respectively putting off dental visits till they have dental problems ${ }^{16}$. Toothbrush and toothpaste use was $97.4 \%$ among the students, which is similar to $95.4 \%$ and $96.6 \%$ reported among Nigerian dental1 and Indian medical and denta ${ }^{17}$ students respectively but different from a study ${ }^{18}$ where all the students used toothbrush and toothpaste. The frequency of twice daily tooth brushing among medical and dental students in Nigeria was $54.7 \%$ compared to students in Australia $(80 \%)^{21}$ and Mongolia $(81 \%)^{6}$ but was higher than $27.5 \%, 47.5 \%$ and $51.3 \%$ reported among dental students in previous Kenyan ${ }^{22}$, Nigerian ${ }^{1}$, and Saudi Arabian18 studies respectively. The reason for these variations cannot be explained, but since this relates more to practice rather than knowledge, it may reflect cultural differences among these populations. As already suggested, there appears to be a gap between the knowledge base of students, as taught in their preventive medicine and dentistry courses, and their oral hygiene practices ${ }^{1}$. About a fifth of the students (21.3\%) still consume sugary snacks in between meals, a figure that is lower to what was observed in previous studies in Nigeria ${ }^{1} \operatorname{Iran}^{3}$ and in Mongolia ${ }^{6}$. The reason for this observed disparity cannot be readily explained. The possible role of socio-economic and cultural differences in oral health behaviours due to the role placed by socioenvironmental factors in oral health behaviours may be a key consideration ${ }^{23}$. Only a little proportion of the students (4\%) did not know that smoking tobacco causes oral health problems. In consonant with this, only $2 \%$ of the students use tobacco products, similar to $1 \%$ reported by Kamble et al., in their study on oral hygiene awareness and practices among medical students in Karnataka India ${ }^{24}$ but lower than the $26 \%, 24 \%$ and $47 \%$ observed among dental students in Turkey ${ }^{2}$, Norway and Greece $^{25}$ respectively. It is also lower than $8.4 \%$ observed in a previous Nigerian study ${ }^{1}$. Smoking is a life style habit and many young people are addicted to it. The low prevalence of smoking among students in Nigeria might be due to the socio-cultural norms where smoking and alcohol use is highly frowned upon ${ }^{1}$. Pertaining to oral health behavior, the majority (53.3\%) of students had poor practice of oral health, which correlates to the proportion $(50 \%)$ of the students noticed to have poor oral hygiene on examination. This shows a disparity between the students' good oral health knowledge and their oral health practice, as also observed among dental students in Nigeria ${ }^{1}$ and both dental and medical students in India ${ }^{17}$. The oral health status of students in this study also showed that $30 \%$ of them had dental caries, $9.3 \%$ had fractured teeth, $1.3 \%$ used dentures and $7.3 \%$ had soft tissue lesions. This might be the reason why about $20 \%$ of students described the health of their teeth and gum as poor. Bleeding as a clinical sign and symptom of unhealthy gum was reported by $29 \%$ of students in a study on oral hygiene and gingival status of dental students in the United Arab Emirates ${ }^{26}$. In this present study ${ }^{3}(2.0 \%)$ students reported that they want their oral health improved. Although there was no significant relationship between oral health practices and demographic characteristics of the students, dental students had a better practice score than medical students which is at variance with a previous study on knowledge, attitude and practice of oraldental health among dental and pharmacy students where the reverse was the case ${ }^{16}$. Males in the present study had better oral health practices compared to females similar to reports observed in previous studies amongst Iranian ${ }^{2}$ and Indian ${ }^{20}$ students. This is in contrast to findings from previous studies undertaken among dental students in India ${ }^{17}$ and United Arab Emirates ${ }^{26}$ where females had better oral health practices. Recent reports have highlighted that oral disorders have emotional and psycho-social impacts on daily life. ${ }^{27}$ In our study, between $3.3 \%$ and $20.7 \%$ of students reported some form of psychosocial impact of their oral health on daily activities, commoner among the younger aged students. The influence of age on the prevalence of psychosocial impact may be due to differing subjective perceptions of social demands among the age groups. In our study, the probability of bias due to misconceptions and errors in interpretation of concepts that exist in studies using self-administered questionnaires with lay population is reduced since all study participants were medical and dental students ${ }^{28}$. However, there might be certain amount of measurement error in handling self-care reported assessments in the present study instead of observed behaviours. Further research is recommended among medical and dental students from other Nigerian universities to allow for generalization. In conclusion, there was a high level of 
good knowledge of oral health care among these Nigerian Medical and Dental students which does not impact appreciably on their oral health care practices. Dental students had better knowledge of oral health care than their medical counterparts. Younger age group of students reported higher psychosocial impact of oral health care on daily activities than older ones.

\section{ACKNOWLEDGEMENTS}

Our appreciation goes to Prof Juliana Taiwo for helping to read the final draft manuscript. This study did not receive any financial support.

\section{REFERENCES}

1. Folayan M.O, Khami M.R, Folaranmi N, et al. Determinants of preventive and oral health behavior among senior dental students. BMC Oral Health 2013; 13: 28.

2. Yidz S, Dogan B. Self-reported dental health attitude and behavior of dental students in Turkey Eur J Dent. 2011; 5: 253-259.

3. Khami M.R, Virtanen J.I, Jafarian M, Murtomaa $H$. Oral health behaviour and its determinants amongst Iranian dental students. Eur J Dent Educ. 2007; 11: 42-47.

4. Freeman R. The determinants of dental health attitudes and behaviour. Br Dent J 1999; 187: 15-81.

5. Polychronopoulou A, Kawamura M, Athanasouli T. Oral self-care behavior among dental school students in Greece. J Oral Sci2002; 44: 73-78.

6. Tseveenjav B, Vehkalahti M, Murtomaa H. Oral health and its determinants among Mongolian dentists. Acta Odontol Scand 2004;62: 1-6.

7. Brown G, Manogue M, Rohlin M. Assessing attitudes in dental education: is it worthwhile? $\mathrm{Br}$ Dent J 2002; 193: 703-707.

8. Cortes F.J, Nevot C, Ramon J.M, Cuenca E. The evolution of dental health in dental students at the University of Barcelona. J Dent Educ2002; 66: 1203-1208.

9. Al-Omari Q.D, Hamasha A.A. Gender specific oral health attitudes and behavior among dental students in Jordan. J Contemp Dent Pract 2005; 15: 107-114.

10. Kawamura M, Honkala E, Widström E,Komabayashi T. Cross-cultural differences of self-reported oral health behaviour in Japanese and Finnish dental students. Int Dent J 2000; 50 : $46-50$.

11. Kaw a mura M, Spadafora A, Kim K.J,Komabayashi T. Comparison of United States and Korean dental hygiene students using the Hiroshima university dental behavioural inventory (HU-DBI). Int Dent J 2002; 52: 156-162.

12. World Health Organization. Diet, nutrition and the prevention of chronic diseases, WHO Technical Report Series 916. Geneva: World Health Organization; 2003.

13. McGonaughy FL, Lucken K.M, Toevs S.E. Health promotion behaviors of private practice dental hygienists. J Dent Hyg1991; 65:222-230

14. Kish L. (1965). Survey Sampling. John Wiley and Sons, Inc. New York.

15. World Health Organization. Oral Health Surveys Basic Methods 5th Edition.

16. Usman S, Bhat S.S, Sargod S.S. Oral health knowledge and behavior of clinical medical, dental and paramedical students in Manglore. J Oral Health Comm Dent 2007; 1: 46-48.

17. Kumar H, Behura S.S, Ramachandra S, Nishat R, Dash K.C, Mohiddin G. Oral health knowledge, attitude, and practices among dental and medical students in Eastern India - a comparative study. J Int Soc Prevent Community Dent 2017; 7: 58-63.

18. Aljrais M.M, Ingle N, Assery M.K. Oral-dental health knowledge, attitude and practice among dental and pharmacy students at Riyadh Elm University, KSA. J Int Oral Health 2018; 10: 198205.

19. Daya D, Teja U, Paturu D.B, et al. Evaluation of oral-hygiene awareness and practice among dental students. J NTR Univ Health Sci 2017; 6: 24-28.

20. Ahamed S, Moyin S, Punathil S, Patil N.A, Kale V.T, Pawar G. Evaluation of the oral health knowledge, attitude and behaviour of preclinical and clinical dental students. J Int Oral Health 2015; 7: 65-70.

21. Messer L.B, Calache H. Oral health attitudes and practices of final-year dental students. Eur J Dent Educ 2012; 16: 144-155.

22. Benjamin S.N, Gathece L.W, Wagaiyu E.G. K n o w led ge, A t t it u d e a n d U s e of Mouthwash among Dental and Medical Students of the University of Nairobi. Int J D e $\mathrm{n}$ t O ral Hea $\mathrm{lth} 2$ 016 ; 2 : d o i http://dx.doi.org/10.16966/23787090.198. 
23. Kawamura M, Wright F.A, Declerck D, et al. An exploratory study on cultural variations in oral health attitudes, behaviour and values of freshman (first-ar) dental students. Int Dent J 2005; 55: 205-211.

24 Kamble V.S, Biradar S.M, Takpere A, Reddy S. Evaluation of oral hygiene awareness and practices among medical students. Int J Community Med Public Health 2016; 3: 83-85.

25. Smith D.R, Leggat P.A. An international review of tobacco smoking among dental students in 19 countries. Int Dent J 2007; 57: 452-458.

26. Rahman B, Kawas S.A. The relationship between dental health behavior, oral hygiene and gingival status of dental students in the United Arab Emirates. Eur J Dent 2013; 7: 22-27.

27. Idon P.I, Suleiman I.K, Bako Y.H, Ngene F.N, Idon M.I, Yusuf J. A Survey of Impact of Oral Health on Quality of Life and its Determinants among Healthcare Workers in a Tertiary Hospital. Glob J Med Res-K Int 2017; 17: 19-26.

28. Sjöström O, Holst D, Lind S.O. Validity of a questionnaire survey: the role of non-response and incorrect answers. Acta Odontol Scand 1999; 57: 242-246. 